\title{
How do Guiana dolphin (Sotalia guianensis), from the Cananéia estuary in State of São Paulo, use cerco-fixo fish traps in their fishing activities?
}

\author{
CAIO NORITAKE LOUZADA ${ }^{1,2}$ \\ ${ }^{1}$ Cananéia Research Institute-IPeC
}

\begin{abstract}
In the Cananéia estuary there is a rare positive interaction between a cetacean and a type of fishing activity. In this region the Guiana dolphin (Sotalia guianensis) uses cerco-fixo fish traps to corner shoals and reduce the escape routes of their prey, and in doing this increase their capture efficiency. The object of this study was to evaluate, by means of a quantitative analysis, how the Guiana dolphin uses the cerco-fixo fish trap in their fishing activities. Their behaviors were quantified separately according to a group structure, so as to also verify how their behaviors vary according to the number of individuals involved in the strategy. This approach serves to improve understanding about what the role of the trap in fishing strategies is and how its use, such as using it as a shield to block the shoals, influences the frequency of behaviors executed during fishing activities.
\end{abstract}

Keywords: Cetacean; fishing behaviour; interspecific interaction; foraging; artisanal fishing.

\section{Introduction}

In the vast majority of cases, interaction between cetaceans and humans have negative aspects for both species. In general, the animal ends up dead whilst tangled up in the fishermen's nets and, in turn, the fisherman suffers financial losses as a result of losing fishing equipment (Read, Drinker \& Northridge, 2006). However, there are rare exceptions where both parties derive benefits from interaction (see Busnel, 1973; Monteiro-Filho, 1995; Simões-Lopes, Fabián \& Menegheti, 1998; Smith et al., 2009; Daura-Jorge et al., 2012).

Specifically, on the southeastern Brazilian coast, there is a small cetacean, referred by local fishermen as boto-cinza (Sotalia guianensis, CETACEA, DELPHINIDAE) (Guiana dolphin) that interacts with fish traps built inside the Cananéia estuary, namely, the cerco-fixo fish traps. When looking for food, the Guiana dolphins occasionally lead the shoals toward the beaches where the traps are situated, the purpose of this action being to reduce the number of possible escape routes open to their prey (Monteiro-Filho, 1995). When the shoal approaches the trap structures, at the same time as the dolphins' attack, it scatters from its initial formation and splits, which aids the dolphins in their capture (Landeau \& Terborgh, 1986). During this attempted escape, some fish end up entering the cerco-fixo fish traps. From the fishermen's point of view, this behavior increases the capture of fish by this fishing equipment (Monteiro-Filho, 1995).

While using a differentiated quantitative approach, Louzada, Filla \& Minte-Vera (manuscript in preparation) confirmed that the presence of these dolphins, while executing their fishing activities around these cerco-fixo fish traps, resulted in there being a high probability of increasing the number of fish caught inside the fishing traps, thereby benefiting the fishermen. However, other factors may influence the trap's production and the amount of fish entering the cerco-fixo fish trap with help from the dolphins. Different fishing behaviors that are carried out in the areas close to the cerco-fixo trap can be attributed to one of these factors, some possibly being more efficient than others. Thus, this study proposes to quantify the different fishing behaviors that are performed on a beach with cerco-fixo fish traps and also to serve as the basis for future studies that will evaluate this strange interaction more deeply.

\footnotetext{
* Correspondence: Caio Noritake Louzada, Instituto de Pesquisas Cananéia. Rua Tristão Lobo, nº 199, Centro, CEP 11990-000, Cananéia - São Paulo. E - mail: caio.noritake@gmail.com

2 Post-Graduate Program in ecology and conservation-UFPR, Paraná
} 
Fishing behavior in Sotalia guianensis and the cerco-fixo

\section{Methods}

Area of study

The study was carried out in the Cananéia Estuarine-Lagoon Complex, one of the most preserved ecosystems along the Brazilian coast, which is located south of the State of São Paulo (SchaefferNovelli, Mesquita\& Cintrón-Molero, 1990). Part of the region is legally protected by state and federal Environmental Protection Areas act. It is $110 \mathrm{~km}$ long and is made up by Ilha (island) Comprida to the east, Ilha do Cardoso to the south, Ilha de Cananéia in the center and the mainland to the West. Between the three islands there is a bay formation called Trapandé Bay (Figure 1).

In the region, there are an abundant amount of natural resources that are exploited by the local population through, for example, fishing and mariculture. Both are important economic activities (Mendonça \& Katsuragawa, 2001). One non-industrial fishing model that happens exclusively within the estuary is the cerco-fixo fishing art. This fishing model provides a generous production of mugil (Mugil sp) and silver mullet (Mugil curema) (Mendonça \& Katsuragawa, 2001).

The area chosen to perform fishing behavior observations of Sotalia guianensis is characterized by its

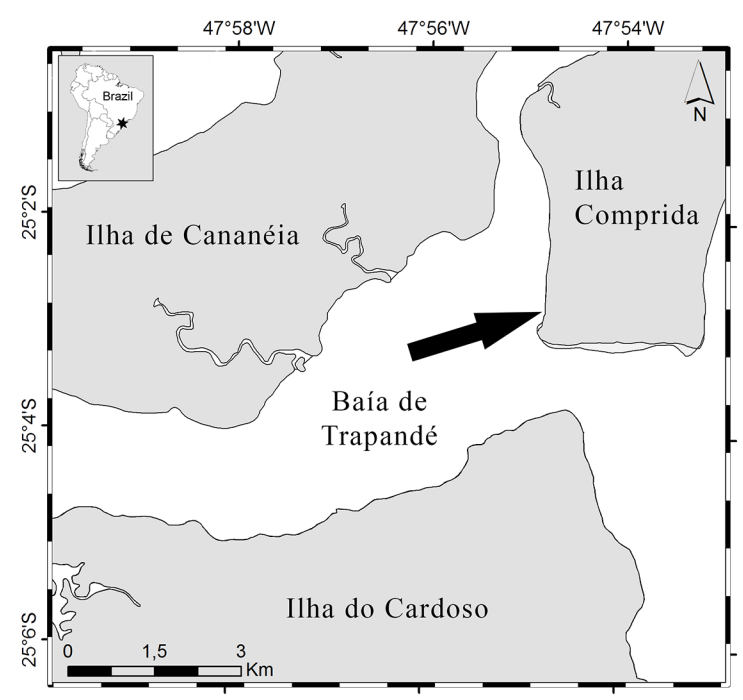

Figure 1: The Cananéia Estuarine-Lagoon Complex Sector, South coast of São Paulo State, where the study of the interaction between Guiana dolphins and the art of cerco-fixo fishing was developed. The arrow indicates the beach where the interaction between dolphins and the cerco-fixo fish trap was studied. having a slightly inclined beach. This characteristic makes the construction of cerco-fixo fish traps possible (Dias, 1990) and also allows Guiana dolphins to approach for fishing purposes (Monteiro-Filho, 1995). The number of cerco-fixo traps installed on the study site's beaches ranged from one to three, depending on the time of year.

The cerco-fixo trap is a fixed trap, handmade by fishermen from bamboo, stakes, galvanized wires and canvases (de Oliveira \& Hanazaki, 2011). In the Cananéia region the structure is built into the estuary's waters, at right angles to the edge of the mangroves. These protected waters are more conducive for the construction of fixed traps and mean that they only need to be relatively durable, since in this kind of environment there is no direct wave influence from the open ocean (Dias, 1990).

\section{Procedures}

From April, 2011 to March, 2012, two monthly field expeditions were conducted in order to observe the fishing behavior of Guiana dolphins close to the cerco-fixo trap structures. The expeditions were carried out in sea conditions that were favorable for observation (a maximum of Beaufort scale 3). Observations were performed with a mixture of focal animal and sequential sampling with information being continuously recorded, divided into 5 minute sections for standardization and repetitions for the same individual/group for a maximum of five sections.

Sotalia guianensis fishing behavior has already been described in previous studies performed in the region (Monteiro-Filho, 1992, 1995) (Table 1). In addition to the dolphin's behavior, their group's structure and the presence of infants were also recorded. The group structure categories that were used followed the descriptions made for the local population of Guiana dolphins (Monteiro-Filho, 2000). The categories used were: "families", which are groups with one or two adults and an infant; "solitary" individuals; "small groups" of three to seven individuals, containing infants and juveniles, or not; and "large groups" which are the groups with eight or more individuals with infants and juveniles, or not. In order to delimit observations to only include individuals/ groups who are interacting with the cerco-fixo traps, only those animals present in a radius of up to 30 meters of each trap were observed.

Later, with the purpose of analyzing more extensively if the variations in the frequency of fishing 


\section{Caio Noritake Louzada}

Table 1. Fishing behavior as already described for Sotalia guianensis in the Cananéia estuary, São Paulo, Brazil.

Behaviors

Description
References

Pursuit

The individual pursues the shoal in a lying position (one of the pectoral fins towards the surface and another in the opposite direction). The dolphin accelerates towards the shoal and attacks the fish from above, close to the surface. The stun and capture method for the fish can be slightly varied.

After pursuing the shoal the dolphin performs a side-shift, attacking into the

Splashing shoal. This movement generates intense water movement on the surface and causes the shoal to split, enabling the dolphin to capture the fish.

After herding the shoal to shallow waters the dolphin quickly rotates its body

Pursuit with laterally and ventrally, perpendicular to the beach line and quickly attacks the

body balance shoal, chasing it - or performing a darting move to finish.

After detecting a shoal, the dolphin performs a deep dive, positions itself

behind the shoal and, while still underwater, releases a curtain of expanding

Pursuit with air bubbles that rise to the surface. This barrier of bubbles prevents the shoal's 1

bubbles escape and forces it to go in the opposite direction, reducing possible escape routes and thereby facilitating fish capture.

\begin{tabular}{|c|c|c|}
\hline $\begin{array}{l}\text { Pursuit with } \\
\text { jumps }\end{array}$ & $\begin{array}{l}\text { In this behavior, during the pursuit of the shoal, the dolphins move quickly to } \\
\text { the surface of the water, exposing its body and alternating its movement by } \\
\text { jumping close to the surface or with jumps in a parabola. }\end{array}$ & 2 \\
\hline $\begin{array}{l}\text { Pursuit with } \\
\text { capture on the } \\
\text { surface }\end{array}$ & $\begin{array}{l}\text { After chasing and directing the shoal close to the surface, the dolphin hits } \\
\text { the prey with the end of its beak and throws the fish out of the water. The } \\
\text { individual can capture the fish in the air or not. }\end{array}$ & 2 \\
\hline Cross-fishing & $\begin{array}{l}\text { This occurs when the dolphins are working together. Initially the individuals } \\
\text { dive toward the shoal along the same lines, subsequently the trajectories of the } \\
\text { diving dolphins intersect. }\end{array}$ & 1 \\
\hline $\begin{array}{l}\text { Pursuit with } \\
\text { tail slap }\end{array}$ & $\begin{array}{l}\text { This behavior begins with a pursuit, then the animal subsequently turns its } \\
\text { body on the surface with its beak pointed downwards. With its tail exposed on } \\
\text { the surface, it beats beats the water in order to separate the shoal or stun its } \\
\text { prey. This action can be repeated several times. }\end{array}$ & 2 \\
\hline Blocking & $\begin{array}{l}\text { This behavior occurs when the shoal is next to an cerco-fixo fish trap and is } \\
\text { always performed by a dyad. While one dolphin dives and attacks the shoal, } \\
\text { another dolphin blocks the escape routes, performing consecutive dives in the } \\
\text { same location. The dolphins' positions are exchanged throughout this strategy. }\end{array}$ & 1 \\
\hline $\begin{array}{l}\text { Fishing in } \\
\text { siege }\end{array}$ & $\begin{array}{l}\text { This often involves a large number of animals working together, forming large } \\
\text { groups. The animals position themselves at the periphery of the shoal while } \\
\text { some attack the edges and from underneath, while others force the shoal to } \\
\text { remain as one cohesive unit. }\end{array}$ & 1 \\
\hline
\end{tabular}


Fishing behavior in Sotalia guianensis and the cerco-fixo

Table 1. Fishing behavior as already described for Sotalia guianensis in the Cananéia estuary, São Paulo, Brazil. (continuation)

\begin{tabular}{|c|c|c|}
\hline Behaviors & Description & References \\
\hline Tracking & $\begin{array}{l}\text { This behavior is only observed in shallow regions of water, in which the } \\
\text { animal, while part of its body is exposed on the surface, adopts a curved } \\
\text { posture with its face facing toward the bottom. This position is maintained for } \\
\text { a few seconds, in which time the animal can still move its head up and down } \\
\text { while it disturbs the substrate in search of prey or possibly to emit sonar. }\end{array}$ & 1 \\
\hline Herding & $\begin{array}{l}\text { When there is a shoal near the beach, one or more dolphins move to deeper } \\
\text { water, they then come up positioned behind the shoal and drive it to shallow } \\
\text { water where they can attack using other behaviors in order to catch the fish. }\end{array}$ & 1 \\
\hline
\end{tabular}

${ }^{1}$ Monteiro-Filho, 1995; ${ }^{2}$ Monteiro-Filho, 1992

behaviors were related to the structure of the group that used the site for fishing, the relative frequencies of each behavioral event were calculated separately according to the categories of the used groups.

So as to analyze the frequencies of fishing behavior and the observed groups' structures, relative frequency was calculated for each category and the adhesion was subsequently compared using a Chi-square test with a $5 \%$ significance level having been set.

\section{Results}

The field effort totaled 96.5 hours, in which it was possible to perform behavioral observations of the dolphins for $17 \%$ of the time. Approaches made to the cerco-fixo trap structures occurred at different frequencies for each group type $\left(\chi^{2}=67.07\right.$;f $=3 ; \mathrm{p}$ $<0.001)$. In most of these observations, the category that approached the cerco-fixo traps closest was the families $(52 \%)$, followed by the solitary individuals $(34 \%)$ and lastly by the small groups $(13 \%)$ (Figure

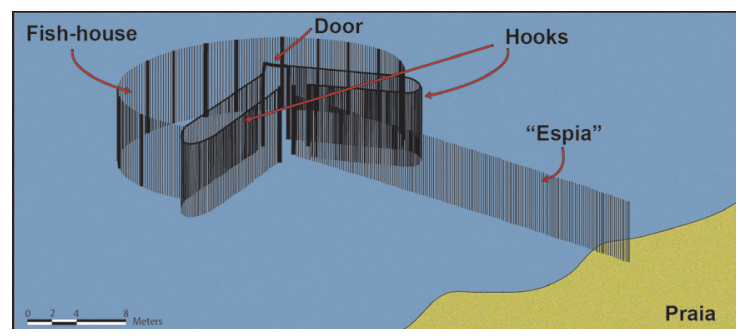

Figure 2.Schematic of a cerco-fixo fish trap structure from the Cananéia region, São Paulo, Brazil. 3a). There were no cases where groups with eight or more individuals were sighted.

For $88 \%$ of the time, individuals used the area for fishing, while for the rest of the time the groups showed themselves in a state of displacement $(5 \%)$ or playing games and learning activities $(2 \%)$ (Figure $3 \mathrm{~b})$. In $5 \%$ of cases it was not possible to clearly determine what the behavioral state of the individuals was, this was mainly due to the short duration spent in the observation area.

From the fishing behaviors performed by Sotalia guianensis, in areas near the cerco-fixo traps, the most frequent types of observed behavior were pursuit $(34 \%)$, followed by splashing $(32 \%)$ and herding $(21 \%)$. These three events total $87 \%$ of all types of behavior in the time period. The other behaviors were cross-fishing (5\%), pursuit with body balance $(5 \%)$ and pursuit with bubbles $(1 \%)$, these occurred at very low frequencies and totaled only $11 \%$ of observed behavior. Pursuit with jumps and pursuit with capture on the surface are rarely observed in this region near the cerco-fixo traps and together represent only $2 \%$ of all observed behavior. Some behavior that was described for the local population of Guiana dolphins were not observed in this area, as for example, pursuit with tail slap, blocking, fishing in siege and tracking.

When analyzing the frequency of fishing behavior performed by each group structure category, there were no differences in the pursuit and splashing behaviors among the analyzed categories $\left(\chi_{\text {Pursuit }}^{2}=2.74 ; \mathrm{df}=2 ; \mathrm{p}=0.253 ; \chi_{\text {splashing }}^{2}=0.203\right.$; 
(a)

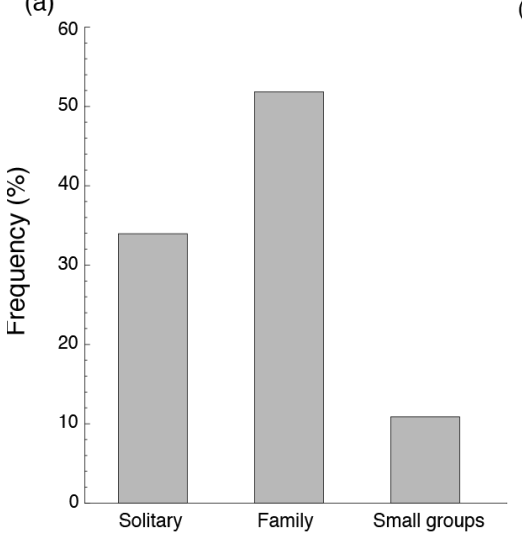

(b)

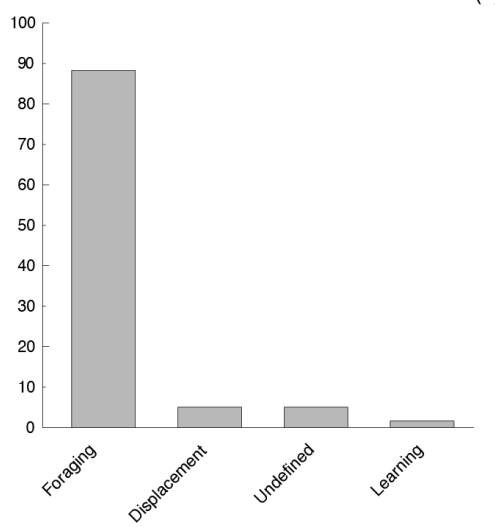

(c)

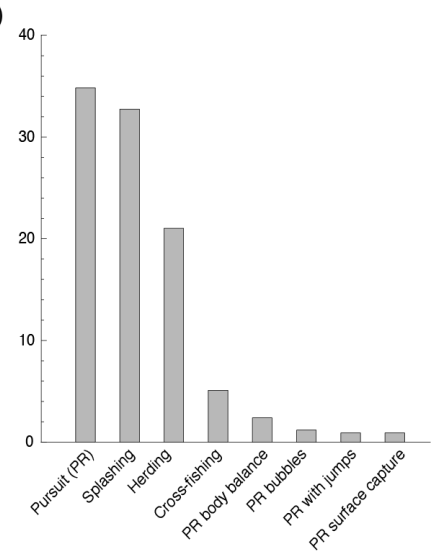

Figure 3. (a) Frequency of group structures observed in the study area, beach with cerco-fixo fish traps installed. Solitary: an individual; Family: an adult or two adults and an infant; Small groups: from three to seven adult individuals possessing infants or not. Groups with more than eight individuals were not observed using this study area. (b) Frequency of observed behavioral states. (c) Frequency of observed fishing behaviors. Pursuit (PR); Splashing; Herding; Cross-fishing; PR body balance: pursuit with body balance; PR bubbles: Pursuit with bubbles; PR with jumps: pursuit with jumps; PR surface capture: pursuit with capture on the surface. For a description of the behaviors see table 1.

$\mathrm{df}=2 ; \mathrm{p}=0.903)$ (Figure 4). On the other hand, the third most frequent herding behavior was executed more frequently by solitary individuals and families $\left(\chi_{\text {Herding }}^{2}=8.35 ; \mathrm{gl}=2 ; \mathrm{p}=0.015\right)$ (Figure 4). Pursuit with body balance was performed evenly among the three categories $\left(\chi_{\text {Body balance }}^{2}=1.88 ; \mathrm{gl}=2 ; \mathrm{p}=0.38\right)$ (Figure 4). Pursuit with bubbles was more frequent with solitary individuals when compared with families $\left(\chi_{\text {Bubbles }}^{2}=10.02 ; \mathrm{gl}=1 ; \mathrm{p}=0.002\right)$ (Figure 4). Pursuit with jumps and pursuit with capture on the surface occurred in very low frequencies and were only executed by families $(1 \%)$.

\section{Discussion}

Studies on how Guiana dolphins use certain areas for fishing activities are important in demonstrating the behavioral plasticity of the species and how the environment possibly influencing strategies for capturing prey (Perry \& Pianka, 1997). This has already been described for some marine mammals that exhibit specific behaviors in certain areas, mainly because of what the environmental features allow them to do (Lewis \& Schroeder, 2003; Pusineri et al., 2007; Visser et al., 2008).

This case study shows a particular situation, because in addition to the environmental characteristics, such as the beach relief, the individuals used manmade structures to improve their fishing efficiency. By herding the shoals to the beaches with the cerco-fixo traps, the dolphins decreased the number of possible escape routes open to the shoals (Monteiro-Filho, 1995). And when executing such attacking behaviors against these shoals, the shoals lost their formation,

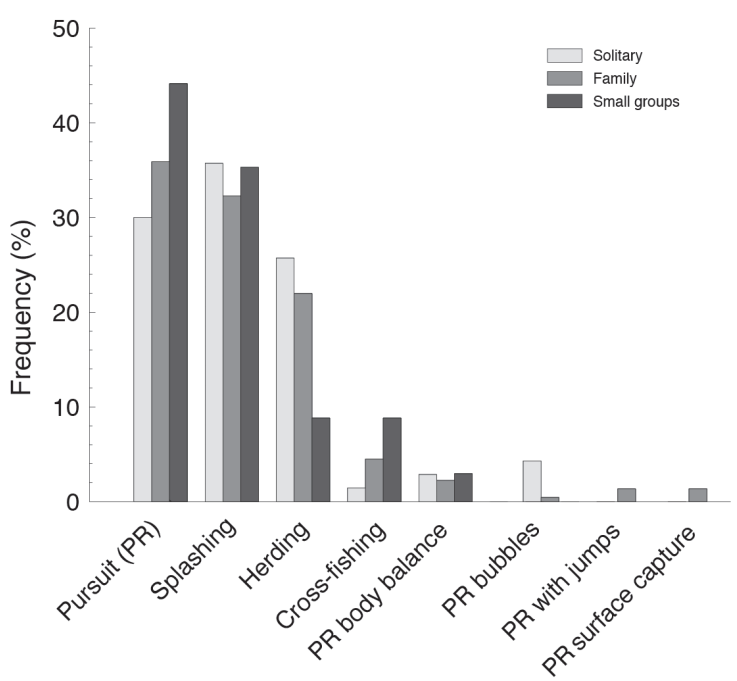

Figure 4. Frequency of fishing behavior quantified separately for each of the observed group structures. Solitary: an individual; Family: an adult or two adults and an infant; Small groups: three to seven individuals with infants or not. Pursuit (PR); Splashing; Herding; Crossfishing; PR body balance: pursuit with body balance; PR bubbles: Pursuit with bubbles; PR with jumps: pursuit with jumps; PR surface capture: pursuit with capture on the surface. For a description of the behaviors see table 1. 
which made it easier for the dolphins to capture their prey (Landeau \& Terborgh, 1986).

Solitary individuals who are not common in other areas of the Cananéia estuary (MonteiroFilho, 2000), were the second most frequent group observed in this study. This fact is probably as a result of the presence of the cerco-fixo traps that allows execution of fishing strategies, and even allows individuals to be successful in their fishing endeavors. There were no groups observed in this study area with eight or more individuals. This kind of grouping occurs in more specific situations such as when executing large displacements or capturing shoals in open areas and at greater depths such as in the open sea (Monteiro-Filho, 2000).

The great predominance of fishing activities performed in the area by Sotalia guianensis shows the importance of this area for obtaining food resources by the individuals who use the estuary. Here, the behavioral state called learning represents a state where individuals, in full interaction with the objective, function in some way to instruct the younger individuals. However in all cases when infants are involved along with the adults during fishing activities, they are naturally accustomed to the procedures for obtaining food. Therefore, it can be said that this area is essential both for fishing and for learning.

The most frequent observed behavior was chasing. This behavior is characterized by their approach in relation to the shoal and can present a wide variety of finishing moves in order to stun and capture the fish, which will then become part of other behaviors. However in many cases, chasing will not result in the dolphin achieving its ultimate goal of catching the prey, thus the behavior is interrupted without a final attack on the shoal. This can justify the more frequently observed occurrence of this behavior. The second most frequent behavior was splashing, it is one of the strategies used as the finishing move of a chase. In this case, after cornering the fish in places where their escape routes are reduced, the Guiana dolphin laterally darts into the shoal so as to divide it. The high frequency of this finishing move, when compared to other behaviors, which are also capture models after chasing, can be attributed to the presence of cerco-fixo traps in the area, since they facilitates the trapping of shoals and provide better opportunities for the dolphins to attack them. This greater splashing frequency can also be attributed in relation to other finishing move behaviors, which is possibly more effective for capturing fish than the others.
The third most frequent behavior was herding. This behavior is of great importance as it allows the dolphins to use the area for food, since when the is a scarcity of food in the area, the individuals move to other sites and then return leading the shoal to the shallow regions with the fixed traps, thereby using the cerco-fixo traps as a shield which allows more efficient prey capture behaviors (Monteiro-Filho, 1995).

When separately quantifying behavior according to the structure of the group that executed it, it was noted that pursuit and darting occurred at the same frequency for the three categories. The equal frequency of darting shows the importance of this type of final move in the fish capture process when using the cerco-fixo trap as a shield, regardless of the number of individuals involved. And possibly because pursuit is a behavioral that is a base for other behaviors, this is executed indiscriminately among the categories.

Herding was a behavior that occurred at equal frequencies for both solitary individuals and families, but less frequently in small groups. This shows that a large number of individuals involved in a strategy allows other behaviors to be executed, such as cross-fishing, which was performed more frequently by small groups. Particularly for this behavior, the presence of a larger number of individuals makes it possible to trap shoals and thereby enable the dolphins to capture their prey without the necessity of driving the shoal to areas where cerco-fixo traps are present, as would happen when herding.

In the last case, the behaviors of pursuit with bubbles, pursuit with jumps and pursuit with capture on the surface were specific to a determined group structure. The higher frequency of chasing with bubbles performed by lone individuals suggests that, on many occasions the chasing of a shoal without the involvement of other individuals may be less effective and it is therefore necessary to adopt other strategies that include the role of other individuals. In this case, the creation of a barrier, by means of air bubbles released by dolphin acts to decrease escape routes open to the shoals

Quantification of fishing behavior in areas where cerco-fixo fishing traps are present helps to better understand how Sotalia guianensis use these strategies in their feeding activities and how the presence of traps increase the effectiveness of prey capture in a great number of situations. This reinforces the idea that this process can be influenced by environmental characteristics (Perry \& Pianka, 1997). Additionally, the the dolphins' use of this area promotes increased 
fish capture in the cerco-fixo traps, thereby further entwining the relationship between man and cetacean. In addition, analysis of behavior frequency, according to group structure, deepens the current knowledge of how Guiana dolphin uses the characteristics of the area, along with a different number of individuals, to create fishing strategies that maximize prey capture.

\section{References}

Busnel, R. G. (1973). Symbiotic relationship between man and dolphins. Transactions of the New York Academy of Sciences, 35(2), 112-131.

Daura-Jorge, F. G., Cantor, M., Ingram, S. N., Lusseau, D., \& Simões-Lopes, P. C. (2012). The structure of a bottlenose dolphin society is coupled to a unique foraging cooperation with artisanal fishermen. Biology Letters, 8, 702-705.

de Oliveira, F. C. \& Hanazaki, N. (2011). Ethnobotany and ecological perspectives on the management and use of plant species is the traditional fishing trap, southern coast of São Paulo, Brazil. Fournal of Environmental Management, 92, 1783-92 17.

Dias, E.R.A. (1990) Produtividade de um cerco-fixo no Parque Estadual da Ilha do Cardoso, na região lagunarestuarina de Cananéia, SP. Em Livro de Resumos. II Simpósio de Ecossistemas da Costa Sul e Sudeste Brasileira: estrutura, função e manejo (p. 400). Águas de Lindóia, SP: Academia de Ciências de São Paulo.

Landeau, L., \& Terborgh, J. (1986). Oddity and the "confusion effect" in predation. Animal Behaviour, 34, 1372-1380.

Lewis, J. S., \& Schroeder, W. W. (2003). Mud plume feeding, a unique foraging behavior of the bottlenose dolphin in the Florida Keys. Gulf of Mexico Science, 21, 92-97.

Mendonça, J. T., \& Katsuragawa, M. (2001). Caracterização da pesca artesanal no complexo estuarino-lagunar de Cananéia-Iguape , Estado de São Paulo, Brasil (1995-1996). Acta Scientiarum. Biological Sciences, 23, 535-547.
Monteiro-Filho, E. L. A. (1992). Pesca associada entre golfinhos e aves marinhas. Revista Brasileira de Zoologia,9, 29-37.

Monteiro-Filho, E. L. A. (1995). Pesca interativa entre o golfinho Sotalia fuviatilis guianensis e a comunidade pesqueira da região de Cananéia. Boletim do Instituto de Pesca, 22(2), 15-23.

Monteiro-Filho, E. L. A. (2000). Group organization of the dolphin Sotalia fluviatilis guianensis in an estuary of southeastern Brazil. Ciência e Cultura fournal of the Brazilian Association for the Advancement of Science, 52(2), 97-101.

Perry, G. \& Pianka, E. R. (1997). Animal foraging: past, present and future. Trends in Ecology \& Evolution, 12, 360-364.

Pusineri, C., Magnin, V., Meynier, L., Spitz, J., Hassani, S., \& Ridoux, V. (2007). Food and feeding ecology of the common dolphin (Delphinus delphis) in the oceanic Northeast Atlantic and comparison with its diet in neritic areas. Marine Mammal Science, 23, 30-47.

Read, A. J., Drinker, P., \& Northridge, S. (2006). Bycatch of Marine Mammals in U.S. and Global Fisheries. Conservation Biology, 20, 163-169.

Schaeffer-Novelli, Y., Mesquita, H. de S. L., \& CintrónMolero, G. (1990). The Cananéia lagoon estuarine system, São Paulo, Brazil. Estuaries, 13, 193-203.

Simões-Lopes, P. G., Fabián, M. E., \& Menegheti, J. O. (1998). Dolphin interactions with the mullet artisanal fishing on Southern Brazil: a qualitative and quantitative approach. Revista Brasileira de Zoologia, 15, 709-726.

Smith, B. D., Tun, M. T., Chit, A. M., Win, H., \& Moe, T. (2009). Catch composition and conservation management of human-dolphin cooperative castnet fishery in the Ayeyarwady River, Burma. Biological Conservation, 142, 1042-1049.

Visser, I. N., Smith, T. G., Bullock, I. D., Green, G. D., Carlsson, O. G. L., \& Imberti, S. (2008). Antarctic peninsula killer whales (Orcinus orca) hunt seals and penguin on floating ice. Marine Mammal Science, 24, 225-234. 